\title{
rs7903146 mutation of Type 2 diabetes mellitus-related gene TCF7L2 is not associated with polycystic ovary syndrome in a cohort of Turkey

\author{
Emre Taşkin ${ }^{1 *}$ (), Semra Eroğlu² (1)
}

\begin{abstract}
SUMMARY
OBJECTIVE: The aim of this study was to investigate whether TCF7L2 gene mutation rs7903146 is in association with polycystic ovary syndrome (PCOS).

METHODS: A total of 44 PCOS and 48 control participants were recruited for this study. After DNA extraction from peripheral blood, quantitative PCR method was used for genotyping. With a case-control study design, two groups were compared for genotype and allele frequencies as well as clinical characteristics.

RESULTS: Mean testosterone level was significantly higher in PCOS group, whereas mean progesterone level was significantly higher in control group. In PCOS group, mean thyroid-stimulating hormone (TSH) level was significantly higher in polymorphic allele carriers. Genotype and allele frequencies were not different between groups.

CONCLUSIONS: When investigated for the first time in a population from Turkey, no association between PCOS and TCF7L2 gene rs7903146 polymorphism was detected. However, considering contradictory results of other populations and low cohort scale of this study, replication studies with greater cohorts are needed.

KEYWORDS: PCOS. TCF7L2. Rs7903146. Polymorphism. Turkey.
\end{abstract}

\section{INTRODUCTION}

Polycystic ovary syndrome (PCOS) is an endocrine disease of women characterized by polycystic ovaries, as well as high levels of androgens, hyperinsulinemia, and absence of ovulation $^{1}$. It is concluded that both genetic and environmental factors cause PCOS condition. However, etiology of the disease is still unclear. Diagnosis of PCOS may be made according to criteria of two consensuses ${ }^{2}$. First, as declared by the US National Institute of Health (NIH) in 1990 and second, as declared by the American Society for Reproductive Medicine (ASRM) and the European Society of Human Reproduction and Embryology (ESHRE) in 2003, which is called Rotterdam criteria $^{3,4}$. According to Júnior Soares et al., ${ }^{2}$ the most recent and accepted consensus is addressed by the Androgen Excess and Polycystic Ovary Syndrome (AES-PCOS) Society who recommends the presence of hyperandrogenism accompanied by chronic anovulation and/or imaging of polycystic ovaries for diagnosis of $\mathrm{PCOS}^{2}$. Clinical manifestations may vary from mild to serious level. Also, women with PCOS are at higher risk of metabolic conditions such as obesity, insulin resistance (IR), and diabetes. IR is one of the most prominent characteristic of the PCOS disease, such that these patients are most likely to develop type 2 diabetes (T2DM) 5 . Also, some PCOS patients may show clinical signs of hirsutism,

\footnotetext{
'Bandırma Onyedi Eylül University, Medical Faculty, Department of Medical Genetics - Bandırma (Balıkesir), Turkey.

${ }^{2}$ Konya Practice Hospital, Başkent University, Medical Faculty, Department of Obstetrics and Gynecology - Konya, Turkey.

*Corresponding author: emretaskin@gmail.com

Conflicts of interest: the authors declare there is no conflicts of interest. Funding: this work was funded by Karabük University, Committee of Scientific Research Projects.

Received on July 03, 2021. Accepted on July 03, 2021.
} 
alopecia, and acne ${ }^{6}$. The pathophysiological features like IR and hyperinsulinemia of T2DM are similar to PCOS, making T2DM-associated genetic variants plausible candidates for PCOS. On the reproductive physiology side, due to hormonal derangement in PCOS, maturated follicles may not function as fertile eggs ${ }^{7}$.

A number of genetic variations have been analyzed and associated with PCOS and selection of the candidate genes investigated before were based on their function and molecular pathway. Also considering approximately $70 \%$ of PCOS patients also develop IR, it is concluded that IR may be closely relevant to etiology of $\mathrm{PCOS}^{8}$. Additionally, IR-related conditions such as normal body mass index and medication for IR improve PCOS clinical condition such as rebalancing hormones and resuming normal ovulation'.

Transcription factor 7-like 2 (TCF7L2) gene resides on chromosome 10q25.2 and has 17 exons with approximately $21.5 \mathrm{~kb}$ length ${ }^{10}$. TCF7L2 is a transcription factor that participates in Wnt signaling pathway, particularly playing a role in maintaining blood glucose levels by repressing proglucagon gene of intestinal endocrine and pancreatic cells ${ }^{11}$. Wnt pathway participates in multiple processes in the cell-like proliferation, apoptosis, and differentiation ${ }^{12}$.

rs7903146 polymorphism is strongly related to T2DM development by Wnt pathway through islet cells of pancreas and interacting with insulin secretion genes ${ }^{13}$. Wnt pathway also regulates proliferation and apoptosis mechanisms of the $\beta$-cells of pancreas, thus has the ability to make changes in the insulin activity ${ }^{14}$. Being multitasking and a key to born and survival of the cell, this pathway was found to be related with many degenerative diseases such as cancer and Alzheimer's diseases. Also, it was shown that in PCOS ovaries, Wnt signaling members display altered expression ${ }^{15}$. Another known effect of Wnt pathway is that adolescent girls with Wnt 4 mutations display hyperandrogenism ${ }^{16}$. Furthermore, TCF7L2 protein induces production of various proteins that are involved in insulin secretion and represses proglucagon synthesis across Wnt pathway ${ }^{17,18}$. The link between TCF7L2 (rs7903146) and PCOS comes from being TCF7L2 a transcription factor of Wnt signaling pathway that is included in diabetes mellitus, a frequent accompanying complication of $\mathrm{PCOS}^{19}$. Also, it was suggested that TCF7L2 gene was expressed in visceral and subcutaneous tissue for regulating glucose homeostasis via Wnt signaling pathway, indicating a possible link between this polymorphism and $\mathrm{PCOS}^{20}$. Also, Lee et al. reported an eye-catching feature of Wnt pathway which activated Wnt pathway in nondiabetic mice fed with high-fat diet ${ }^{21}$. Genetic polymorphisms in TCF7L2 were reported to be clearly associated with T2DM as well as dysfunction of $\beta$ cells $^{22}$. Wnt pathway also referred as Wnt/b-Catenin pathway also has a function of drug metabolism in primary human hepatocytes that may be used for evaluating drug hepatoxicity ${ }^{23}$.

rs7903146 is one of the candidate polymorphisms for the direct association with PCOS among other single nucleotide polymorphisms (SNPs) in the gene. The polymorphic nucleotide resides in an intron, which is a not a coding nucleotide for the protein itself. Since TCF7L2 directly effects insulin secretion that is associated with PCOS, rs7903146 was chosen for investigating its associations with PCOS. Considering its molecular mechanism, TCF7L2 stands as both activator and repressor of Wnt pathway regulatory genes, thus, it is one of the most influential risk genes on developing T2DM condition that is related to $\mathrm{PCOS}^{23}$.

To date, using candidate gene approach, several genes were investigated in terms of their association with PCOS. Since detailed mechanism of PCOS is still unclear, this approach yielded negative results from studies. In GWAS studies, 11 loci out of 70 candidate genes were found associated with PCOS ${ }^{24}$. Thus, when investigating the association of TCF7L2 with PCOS, rs7903146 stands as one of the most plausible SNPs to investigate. To date, association of rs7903146 with PCOS was investigated in the UK, Finland, Tunisia, Greece, Bahrain, Korea, Brazil, India, Czech Republic, and China ${ }^{25}$. Majority of these studies failed to detect the association, except in the study conducted by Greece.

\section{METHODS}

\section{Sample collection}

Case group of 44 and control group of 48 individuals were included in this study from Education and Research Hospital of Karabük University. Control and case groups were matched in regard to their age. Individuals who went to hospital for periodic controls were taken as control group, whereas individuals diagnosed with PCOS according to Rotterdam criteria after clinical examination, laboratory testing, and ultrasonography were taken as case group. Relatives, taking medication, and having chronic diseases were set as exclusion criteria. All subjects were informed and signed written consent. Study protocol was approved by ethics committee of medical faculty of Karabük University.

\section{Biochemical analysis}

About $2 \mathrm{~mL}$ of peripheral blood were draw to EDTA-containing tubes from all participants after 12-h of fasting. Siemens ADVIA Centaur ${ }^{\circledR} \mathrm{XP}$ electrochemiluminescence assay was used for hormone level measurement. Biochemical measurements of 
blood glucose levels were made with ADVIA $^{\circledast} 2400$ Clinical Chemistry System that uses spectrophotometry.

\section{DNA extraction and analysis}

DNA was extracted from leukocytes of peripheral blood according to attached protocol (GF-1 Blood DNA Extraction Kit, Vivantis, Malaysia). Extracted DNA was stored at $-20^{\circ} \mathrm{C}$. Specific primers were designed using Primer3 software ${ }^{26}$. Real-time quantitative PCR method was performed in $20 \mu \mathrm{L}$ PCR mix using Eva Green DNA binding dye (SNP, Turkey). ABI 7,500 Real Time PCR system was used for performing qPCR and analysis of the CT levels (Thermo Fisher Scientific Inc.).

\section{Statistical analysis}

Both groups were detected for Hardy-Weinberg equilibrium by chi-square analysis. Normal distributions of all variables were controlled by using Kolmogorov-Smirnov test. Continuous variables were tested using Student's t-test for variables compatible with normal distribution and given as mean \pm standard deviation. For clinical data not compatible with normal distribution, Mann-Whitney U test was used (progesterone clinical data). Alpha level for statistical significance were determined as $\mathrm{p}=0.05$. Chi-square test was used to determine significant level of genotype and allele frequency distribution between control and PCOS groups. Homogeneity of variances were tested before analysis of variance by Leven's test. ANOVA method was used for testing the differences of clinical data except progesterone between genotypes in PCOS group. Since distribution of progesterone levels do not follow normal distribution, levels between genotypes were tested by Kruskal-Wallis test. For evaluation of effects of genotypes on PCOS, logistic regression analysis was performed. In all tables, data were given for all available subjects.

\section{RESULTS}

Testosterone level of PCOS group was significantly elevated compared with controls $(\mathrm{p}<0.01)$. Progesterone level in control group was significantly increased than that of PCOS group $(\mathrm{p}<0.01)$. Other measurements of clinical data did not give any significant difference between groups (Table 1). In PCOS intragroup comparison between genotypes, only thyroid-stimulating hormone (TSH) level of CT+TT genotypes were significantly higher than that of CC genotype in dominant model $(\mathrm{p}<0.05)$.

Table 1. Clinical data of subjects and comparison of clinical characteristics between genotypes in case group.

\begin{tabular}{|c|c|c|c|c|c|c|c|c|c|c|}
\hline \multirow[b]{2}{*}{ Age (years) } & \multirow{2}{*}{$\begin{array}{c}\text { Controls } \\
(n=33)\end{array}$} & \multirow{2}{*}{\begin{tabular}{|c|}
$P C O S(n=48)$ \\
$23.7 \pm 5.8$ \\
\end{tabular}} & \multirow{2}{*}{$\begin{array}{c}p \\
>0.05 \\
\end{array}$} & \multirow{2}{*}{\begin{tabular}{|c|} 
Case group \\
Genotype \\
\end{tabular}} & \multicolumn{2}{|c|}{ Recessive model } & \multirow[t]{2}{*}{$p$} & \multicolumn{2}{|c|}{ Dominant model } & \multirow[t]{2}{*}{ p } \\
\hline & & & & & $\mathrm{CC}+\mathrm{CT}$ & TT & & CC & $\mathrm{CT}+\mathrm{TT}$ & \\
\hline $\mathrm{BMI}\left(\mathrm{kg} / \mathrm{m}^{2}\right)$ & $24.9 \pm 3.5$ & $24.1 \pm 5.4$ & $>0.05$ & BMI $\left(\mathrm{kg} / \mathrm{m}^{2}\right)$ & $24.3 \pm 5.6$ & $22.5 \pm 3.3$ & 0.45 & $23.5 \pm 5.9$ & $24.5 \pm 5.03$ & $>0.05$ \\
\hline $\begin{array}{l}\text { Insulin } \\
\text { (pmol/L) }\end{array}$ & $127 \pm 50$ & $109 \pm 40$ & $>0.05$ & $\begin{array}{l}\text { Insulin } \\
\text { (pmol/L) }\end{array}$ & $107 \pm 37$ & $99 \pm 36$ & 0.59 & $108 \pm 43$ & $105 \pm 32$ & $>0.05$ \\
\hline $\begin{array}{l}\text { Testosterone } \\
(\mathrm{nmol} / \mathrm{L})\end{array}$ & $1.09 \pm 0.39$ & $1.58 \pm 0.57$ & $<0.01$ & $\begin{array}{c}\text { Testosterone } \\
(\mathrm{nmol} / \mathrm{L})\end{array}$ & $1.59 \pm 0.60$ & $1.53 \pm 0.29$ & 0.831 & $1.46 \pm 0.63$ & $1.68 \pm 0.52$ & $>0.05$ \\
\hline $\begin{array}{l}\text { Fasting } \\
\text { glucose } \\
\text { (mmol/L) }\end{array}$ & $4.96 \pm 0.53$ & $5.04 \pm 0.42$ & $>0.05$ & $\begin{array}{l}\text { Fasting } \\
\text { glucose } \\
\text { (mmol/L) }\end{array}$ & $5.03 \pm 0.44$ & $5.16 \pm 0.28$ & 0.509 & $4.99 \pm 0.44$ & $5.09 \pm 0.41$ & $>0.05$ \\
\hline $\begin{array}{l}\text { Estradiol } \\
\text { (pmol/L) }\end{array}$ & $205.94 \pm 90.31$ & $196.03 \pm 88.84$ & $>0.05$ & $\begin{array}{l}\text { Estradiol } \\
\text { (pmol/L) }\end{array}$ & $204 \pm 89$ & $132 \pm 66$ & 0.086 & $197 \pm 74$ & $195 \pm 101$ & $>0.05$ \\
\hline FSH (IU/L) & $7.67 \pm 2.76$ & $6.96 \pm 2.08$ & $>0.05$ & FSH (IU/L) & $6.81 \pm 1.96$ & $7.91 \pm 2.81$ & 0.227 & $6.90 \pm 2.22$ & $6.98 \pm 2.02$ & $>0.05$ \\
\hline $\mathrm{LH}(\mathrm{IU} / \mathrm{L})$ & $8.13 \pm 3.90$ & $8.59 \pm 4.28$ & $>0.05$ & LH (IU/L) & $8.67 \pm 4.36$ & $7.93 \pm 3.89$ & 0.749 & $8.86 \pm 4.41$ & $8.33 \pm 4.24$ & $>0.05$ \\
\hline $\begin{array}{l}\text { Progesterone } \\
(\mathrm{ng} / \mathrm{mL}) \\
(\mathrm{nmol} / \mathrm{L})^{*}\end{array}$ & $15.45 \pm 12.75$ & $3.85 \pm 7.63$ & $<0.01$ & $\begin{array}{c}\text { Progesterone } \\
(\mathrm{ng} / \mathrm{mL}) \\
(\mathrm{nmol} / \mathrm{L})^{\star}\end{array}$ & $3.65 \pm 7.70$ & $7.55 \pm 3.38$ & 0.408 & $2.05 \pm 1.36$ & $5.29 \pm 10.0$ & $>0.05$ \\
\hline $\begin{array}{l}\text { Prolactin } \\
(\mu \mathrm{g} / \mathrm{L})\end{array}$ & $10.8 \pm 5.18$ & $11.7 \pm 4.68$ & $>0.05$ & $\begin{array}{c}\text { Prolactin } \\
(\mu \mathrm{g} / \mathrm{L})\end{array}$ & $11.58 \pm 4.8$ & $12.90 \pm 3.74$ & 0.6 & $12.63 \pm 4.98$ & $11.01 \pm 4.43$ & $>0.05$ \\
\hline TSH (IU/L) & $2.17 \pm 1.09$ & $2.47 \pm 1.16$ & $>0.05$ & TSH (IU/L) & $2.59 \pm 1.13$ & $1.74 \pm 1.10$ & 0.095 & $2.02 \pm 0.99$ & $2.80 \pm 1.18$ & 0.028 \\
\hline
\end{tabular}

PCOS: polycystic ovary syndrome; BMI: Body mass index; FSH: follicle-stimulating hormone; LH: luteinizing hormone; TSH: thyroid-stimulating hormone. *Progesteron levels were compared by Mann-Whitney U test due to noncomformity to parametric test requirements. Only available data were included. Standard deviations are given after \pm symbol. The values highlighted in bold are intended to draw the reader's attention to statistically significant variables 
Genotype and allele frequency comparison is given in Table 2. There was no difference between groups, either for genotype or for allele frequencies $(\mathrm{p}>0.05)$.

Logistic regression analysis were given in Table 3. For unadjusted and adjusted models, polymorphism did not have effect on placing in any groups ( $\mathrm{p}>0.05$, OR: $1.571,95 \% \mathrm{CI} 0.675-$ 3.657; p>0.05, OR: 1.810, 95\%CI 0.751-4.361, respectively).

\section{DISCUSSION}

Here, we aimed to investigate whether rs7903146 polymorphism of the TCF7L2 gene is in association with PCOS in a population from Turkey. Studies from other countries such as Europe, China, Korea, and Brazil yielded negative results ${ }^{27-31}$. In a population from Tunisia consisting of Arabic and Turkish origins; from Bahrain consisting of Jafari Arabs, Sunni Arabs, and Iranians, association between PCOS and rs7903146 was rejected $^{14,32}$. As the first time in a population from Turkey, our goal was to detect whether there is an association between TFC7L2 gene rs7903146 polymorphism and PCOS as well as to compare the clinical data and elucidate polymorphism frequency of the groups. In this regard, we recruited 44 PCOS and 48 control subjects.

In our comparison of clinical data between groups, we have found that testosterone level was significantly higher in PCOS group compared with controls (Table 1; $\mathrm{p}<0.01$ ). In studies from Greece, Korea, and Brazil, similar testosterone comparison results were reported ${ }^{28,30,33}$. This result is expected since hyperandrogenism displays elevated testosterone levels. This condition physiologically may result from increased production of testosterone from polycystic ovarium. Increased testosterone also may be stimulated by increased insulin levels and IR but we did not detect any significant difference in insulin levels between groups (Table $1 ; \mathrm{p}>0.05$ ). Also, we have found that progesterone level was significantly higher in control group (Table 1; $\mathrm{p}<0.01)$. However in Greece study, progesterone comparison gave contradictory result as being higher in PCOS group ${ }^{33}$. We did not encounter more progesterone level comparison in similar studies. Although higher progesterone levels in PCOS patients is expected due to hyperandrogenism, our result may be due to desensitization of hypothalamus as this condition is also presented in PCOS patients.

In our cohort, genotype and allele frequencies did not represent any significant difference between case and control groups (Table 2; $p>0.05$ ). Our control group was compatible with Hardy-Weinberg equilibrium. In Greece study, polymorphic $\mathrm{T}$ allele frequency was borderline significantly higher in PCOS group creating a weak predisposition to PCOS, although genotype frequencies did not represent an association between rs7903146 polymorphism and PCOS $(\mathrm{p}=0.04)^{33}$. In a cohort

Table 2. Genotype and allele frequency comparison.

\begin{tabular}{|c|c|c|c|c|}
\hline & & Controls $(n=44)$ & $\operatorname{PCOS}(n=48)$ & $p$ \\
\hline \multirow{3}{*}{ rs7903146 n (\%) } & CC & $22(55)$ & $21(44)$ & \multirow{3}{*}{$>0.05$} \\
\hline & $\mathrm{CT}$ & $10(25)$ & $21(44)$ & \\
\hline & $\mathrm{TT}$ & $8(20)$ & $6(12)$ & \\
\hline \multicolumn{2}{|c|}{ Allele frequencies $\mathrm{C} / \mathrm{T}$} & $0.67 / 0.33$ & $0.66 / 0.34$ & $>0.05$ \\
\hline \multirow{2}{*}{ rs7903146 n (\%) } & CC & $22(55)$ & $21(44)$ & \multirow{2}{*}{$>0.05$} \\
\hline & $\mathrm{CT}+\mathrm{TT}$ & $18(45)$ & $27(56)$ & \\
\hline
\end{tabular}

PCOS: polycystic ovary syndrome. Odds ratio for CT+TT between groups is 1,571 (95\%Cl 0.675-3.657).

Table 3. Logistic regression analysis.

\begin{tabular}{|c|c|c|c|c|c|}
\hline & \multicolumn{2}{|c|}{ Unadjusted model } & \multicolumn{2}{|c|}{ Adjusted model $^{*}$} \\
\hline & & OR $(95 \% \mathrm{Cl})$ & p & OR $(95 \% \mathrm{Cl})$ & $p$ \\
\hline \multirow{2}{*}{ Recessive model } & $\mathrm{CC}+\mathrm{CT}$ & 1 & \multirow{2}{*}{0.3} & 1 & \multirow{2}{*}{0.41} \\
\hline & $\mathrm{TT}$ & $0.571(0.180-1.812)$ & & $0.607(0.187-1.970)$ & \\
\hline \multirow{2}{*}{ Dominant model } & $\mathrm{CC}$ & 1 & \multirow{2}{*}{0.3} & 1 & \multirow{2}{*}{0.19} \\
\hline & $\mathrm{CT}+\mathrm{TT}$ & $1.571(0.675-3.657)$ & & $1.810(0.751-4.361)$ & \\
\hline
\end{tabular}

OR: odds ratio; Cl: confidence interval. *Adjusted for age and body mass index. 
from Bahrain, who are ethnically close to Turkey, that includes Turks, rs7903146 was not associated with PCOS $(p>0.05)^{14}$. Similar to this study, Barber et al. ${ }^{28}$ had the largest cohort (369 PCOS patients and 2,574 controls for one study and 540 patients and 1,083 patients for another) consisting ethnicities of British, Irish, and Finnish subject, yet they did not detect any association $(p>0.05)$. In a study with Korean population containing 377 patients and 386 control subjects, again association was lacking between rs7903146 polymorphism and PCOS $(\mathrm{p}>0.05)^{28}$. In a study from India with 248 patients and 210 control subjects, no association also reported $(p>0.05)^{24}$.

We performed intragroup comparison of clinical characteristics for PCOS patients. Unexpectedly, we detected a signifcant difference of only TSH, being higher in polymorphic carriers (CC versus $\mathrm{CT}+\mathrm{TT}$ ) compared with homozygous normal subjects (Table $1 ; \mathrm{p}<0.05$ ). Although subjects who have known thyroid dysfunction were excluded from the study, this difference may result due to unknown impaired thyroid function of included subjects. Another reason may be that TSH is a structurally similar hormone to follicle-stimulating hormone (FSH), thus may increase as a result of positive feedback in the case of hormone imbalance in PCOS patients, especially for polymorphic allele carriers. We are not able to compare this result with other studies, since they did not represent TSH values of case and control groups due to excluding thyroid dysfunction patients from their cohort.

Regression analysis did not show any influence of rs7903146 polymorphism on having PCOS in both unadjusted and adjusted models ( $p>0.05)$. This result is expected since we did not detect any association between the polymorphism and PCOS in chi-square analysis. GWAS studies offered candidate genes for association with PCOS, especially T2DM-related genes. Since PCOS is also an endocrine disorder that is closely related to IR, T2DM-associated genes like TCF7L2 were investigated with GWAS and for association with PCOS. However, many attempts failed to show association with PCOS. Our results that show PCOS is not associated with rs7903146 polymorphism support the conclusion which, although this polymorphism is one of the major genetic determinants of IR, it does not directly affect PCOS.
When we consider case-control studies, the effect of polymorphisms on PCOS seems to be very slight. However, this consideration may result from relatively small sample sizes of conducted studies similar to this study. In this regard, studies with larger cohorts are needed to achieve more powered and accurate statistics.

PCOS susceptibility gene research progress slowly compared with other diseases such as obesity and T2DM. Phenotypic heterogeneity is one of the most preclusive factors which prevents conclusions for which genes and variants may be included in PCOS pathophysiology.

\section{CONCLUSIONS}

Limitation of this study is lower recruited sample size compared with similar studies. On the other hand, strength of this study is being the first investigation of rs7903146 in a population from Turkey and exclusion of diabetes mellitus and other metabolic disease carriers, thus focusing on only the association between PCOS and the polymorphism. In this study, we conclude that rs7903146-coded polymorphism of TCF7L2 gene is not associated with PCOS in a cohort from Turkey. Considering that this is a pilot study that has a lower sample size and contradictory results of similar studies, replicating with a larger and more inclusive cohort that better represents the population of Turkey is recommended.

\section{ACKNOWLEDGMENT}

We thank to Yeliz Eski (MSc) for contributing to laboratory progress of this study.

\section{AUTHORS" CONTRIBUTIONS}

ET: Conceptualization, Data curation, Formal analysis, Funding acquisition, Investigation, Methodology Project administration, Resources, Software Supervision, Validation, Visualization, Writing - original draft, Writing - review \& editing. SE: Conceptualization, Data curation, Investigation, Resources, Visualization, Writing - original draft.

\section{REFERENCES}

1. Ioannidis A, Ikonomi E, Dimou NL, Douma L, Bagos PG. Polymorphisms of the insulin receptor and the insulin receptor substrates genes in polycystic ovary syndrome: a mendelian randomization meta-analysis. Mol Genet Metab. 2010;99(2):17483. https://doi.org/10.1016/j.ymgme.2009.10.013
2. Soares Júnior JM, Baracat MCP, Maciel GAR, Baracat EC Polycystic ovary syndrome: controversies and challenges Rev Assoc Med Bras (1992). 2015;61(6):485-7. https://doi. org/10.1590/1806-9282.61.06.485 
3. Hsu MI, Liou TH, Chou SY, Chang CY, Hsu CS. Diagnostic criteria for polycystic ovary syndrome in Taiwanese Chinese women: comparison between Rotterdam 2003 and NIH 1990. Fertil Steril. 2007;88(3):727-9. https://doi.org/10.1016/j. fertnstert.2006.11.149

4. Rotterdam ESHRE/ASRM-Sponsored PCOS Consensus Workshop Group. Revised 2003 consensus on diagnostic criteria and long-term health risks related to polycystic ovary syndrome. Fertil Steril. 2004;81(1):19-25. https://doi.org/10.1016/j. fertnstert.2003.10.004

5. Sir-Petermann T, Angel B, Maliqueo M, Carvajal F, Santos $J$, Pérez-Bravo F. Prevalence of type II diabetes mellitus and insulin resistance in parents of women with polycystic ovary syndrome. Diabetologia. 2002;45(7):959-64. https://doi. org/10.1007/s00125-002-0836-3

6. Kalantari S, Sharafshah A, Keshavarz P, Davoudi A, Habibipour R. Single and multi-locus association study of TCF7L2 gene variants with susceptibility to type 2 diabetes mellitus in an Iranian population. Gene. 2019;696:88-94. https://doi. org/10.1016/j.gene.2019.01.040

7. Prabhu YD, Sekar N, Abilash VG. Screening of polymorphisms of transcription factor 7-like 2 gene in polycystic ovary syndrome using polymerase chain reaction-restriction fragment length polymorphism analysis. J Hum Reprod Sci. 2018;11(2):137-41. https://doi.org/10.4103/jhrs.JHRS_123_15

8. Moghetti P. Insulin resistance and polycystic ovary syndrome. Curr Pharm Des. 2016;22(36):5526-34. https://doi.org/10.2 174/1381612822666160720155855

9. Norman RJ, Dewailly D, Legro RS, Hickey TE. Polycystic ovary syndrome. Lancet. 2007;370(9588):685-97. https://doi. org/10.1016/S0140-6736(07)61345-2

10. Duval A, Busson-Leconiat M, Berger R, Hamelin R. Assignment of the TCF-4 gene (TCF7L2) to human chromosome band 10q25.3. Cytogenet Cell Genet. 2000;88(3-4):264-5. https:// doi.org/10.1159/000015534

11. Yi F, Brubaker PL, Jin T. TCF-4 mediates cell typespecific regulation of proglucagon gene expression by beta-catenin and glycogen synthase kinase-3beta. J Biol Chem. 2005;280(2):1457-64. https://doi.org/10.1074/jbc. M411487200.

12. Monga SPS. Role of Wnt/ $\beta$-catenin signaling in liver metabolism and cancer. Int J Biochem Cell Biol. 2011;43(7):1021-9. https:// doi.org/10.1016/j.biocel.2009.09.001

13. Bahaaeldin AM, Seif AA, Hamed Al, Kabiel WAY. Transcription factor 7-like-2 (TCF7L2) rs7903146 (C/T) polymorphism in patients with type 2 diabetes mellitus. Dubai Diabetes Endocrinol J. 2020;26(3):112-8. https://doi. org/10.1159/000509756

14. Gammoh E, Mahmood NA, Madan S, Ebrahim BH, Mustafa $\mathrm{FE}$, Almawi WY. Transcription factor-7-like 2 gene variants affect the metabolic phenotypes of polycystic ovary syndrome. Ann Nutr Metab. 2015;67(4):228-35. https:// doi.org/10.1159/000439546

15. Jansen E, Laven JSE, Dommerholt HBR, Polman J, van Rijt C, van den Hurk $C$, et al. Abnormal gene expression profiles in human ovaries from polycystic ovary syndrome patients. Mol Endocrinol. 2004;18(12):3050-63. https://doi.org/10.1210/ me.2004-0074

16. Philibert $P$, Biason-Lauber $A$, Gueorguieva I, Stuckens $C$, Pienkowski C, Lebon-Labich B, et al. Molecular analysis of WNT4 gene in four adolescent girls with mullerian duct abnormality and hyperandrogenism (atypical Mayer-Rokitansky-KüsterHauser syndrome). Fertil Steril. 2011;95(8):2683-6. https:// doi.org/10.1016/j.fertnstert.2011.01.152

17. Jin T. Current understanding on role of the Wnt signaling pathway effector TCF7L2 in glucose homeostasis. Endocr Rev. 2016;37(3):254-77. https://doi.org/10.1210/er.20151146

18. Shen WJ, Li TR, Hu YJ, Liu HB, Song M. Relationships between TCF7L2 genetic polymorphisms and polycystic ovary syndrome risk: a meta-analysis. Metab Syndr Relat Disord. 2014;12(4):210-9. https://doi.org/10.1089/met.2014.0004

19. Logan $C Y$, Nusse R. The Wnt signaling pathway in development and disease. Annu Rev Cell Dev Biol. 2004;20:781-810. https:// doi.org/10.1146/annurev.cellbio.20.010403.113126

20. Wang J, Kuusisto J, Vänttinen M, Kuulasmaa T, Lindström J, Tuomilehto J, et al. Variants of transcription factor 7-like 2 (TCF7L2) gene predict conversion to type 2 diabetes in the Finnish Diabetes Prevention Study and are associated with impaired glucose regulation and impaired insulin secretion. Diabetologia. 2007;50(6):1192-200. https://doi.org/10.1007/ s00125-007-0656-6

21. Lee SH, Demeterco C, Geron I, Abrahamsson A, Levine F, Itkin-Ansari P. Islet specific Wnt activation in human type II diabetes. Exp Diabetes Res. 2008;2008:728763. https://doi. org/10.1155/2008/728763

22. Lyssenko V, Lupi R, Marchetti P, Del Guerra S, Orho-Melander $\mathrm{M}$, Almgren $\mathrm{P}$, et al. Mechanisms by which common variants in the TCF7L2 gene increase risk of type 2 diabetes. J Clin Invest. 2007;117(8):2155-63. https://doi.org/10.1172/ $\mathrm{JCl} 30706$

23. Gerbal-Chaloin S, Dumé AS, Briolotti $P$, Klieber $S$, Raulet $E$, Duret $C$, et al. The WNT/ $\beta$-catenin pathway is a transcriptional regulator of CYP2E1, CYP1A2, and aryl hydrocarbon receptor gene expression in primary human hepatocytes. Mol Pharmacol. 2014;86(6):624-34. https://doi.org/10.1124/ mol.114.094797

24. Lehman DM, Hunt KJ, Leach RJ, Hamlington J, Arya R, Abboud $\mathrm{HE}$, et al. Haplotypes of transcription factor 7-like 2 (TCF7L2) gene and its upstream region are associated with type 2 diabetes and age of onset in Mexican Americans. Diabetes. 2007;56(2):389-93. https://doi.org/10.2337/ db06-0860

25. Reddy BM, Kommoju UJ, Dasgupta S, Rayabarapu P. Association of type 2 diabetes mellitus genes in polycystic ovary syndrome aetiology among women from southern India. Indian J Med Res. 2016;144(3):400-8. https://doi.org/10.4103/09715916.198678

26. Wang X, Wang K, Yan J, Wu M. A meta-analysis on associations of FTO, MTHFR and TCF7L2 polymorphisms with polycystic ovary syndrome. Genomics. 2020;112(2):1516-21. https:// doi.org/10.1016/j.ygeno.2019.08.023

27. Untergasser A, Cutcutache I, Koressaar T, Ye J, Faircloth BC, Remm M, et al. Primer3 -- new capabilities and interfaces. Nucleic Acids Res. 2012;40(15):e115. https://doi.org/10.1093/ nar/gks596

28. Barber TM, Bennett AJ, Groves CJ, Sovio U, Ruokonen A Martikainen $\mathrm{H}$, et al. Disparate genetic influences on polycystic ovary syndrome (PCOS) and type 2 diabetes revealed by a lack of association between common variants within the TCF7L2 gene and PCOS. Diabetologia. 2007;50(11):2318-22. https:// doi.org/10.1007/s00125-007-0804-z 
29. Kim JJ, Choi YM, Cho YM, Hong MA, Chae SJ, Hwang $\mathrm{KR}$, et al. Polycystic ovary syndrome is not associated with polymorphisms of the TCF7L2, CDKAL1, HHEX, KCNJ11, FTO and SLC30A8 genes. Clin Endocrinol (Oxf). 2012;77(3):43945. https://doi.org/10.1111/j.1365-2265.2012.04389.x

30. Lin L, Yang J, Ding Y, Wang J, Ting L. Genetic polymorphisms of TCF7L2 lack influence on risk of the polycystic ovary syndrome a systemic analysis. Asian Pac J Cancer Prev. 2014;15(7):3331-3. https://doi.org/10.7314/apjcp.2014.15.7.3331

31. Ramos RB, Wiltgen D, Spritzer PM. Polymorphisms of TCF7L2 gene in South Brazilian women with polycystic ovary syndrome: a cross-sectional study. Eur J Endocrinol. 2013;169(5):569-76. https://doi.org/10.1530/EJE-13-0105

32. Xu P, Che Y, Cao Y, Wu X, Sun H, Liang F, et al. Polymorphisms of TCF7L2 and HHEX genes in Chinese women with polycystic ovary syndrome. J Assist Reprod Genet. 2010;27(1):23-8. https://doi.org/10.1007/s10815-009-9377-8

33. Ben-Salem A, Ajina M, Suissi M, Daher HS, Almawi WY, Mahjoub T. Polymorphisms of transcription factor-7-like 2 (TCF7L2) gene in Tunisian women with polycystic ovary syndrome (PCOS). Gene. 2014;533(2):554-7. https://doi. org/10.1016/j.gene.2013.09.104 